\title{
Development and Prediction of Flame Retarded Particleboard Fire Behaviour in Real Scale
}

\author{
T.O. Suoware ${ }^{1, *}$, S.I. Umeh ${ }^{2}$ and S.O. Edelugo ${ }^{3}$ \\ ${ }^{I}$ Department of Mechanical Engineering Technology, Federal Polytechnic, Ekowe, NIGERIA. \\ ${ }^{2,3}$ Department of Mechanical Engineering, University of Nigeria, Nsukka, NIGERIA. \\ ${ }^{3}$ African Centre for Excellence, ACE-SPED, University of Nigeria, Nsukka, NIGERIA.
}

\begin{abstract}
Particleboard composites for building application has become very attractive because of their huge benefits which includes but is not limited to low cost, lightweight, durability and environmental benign. However, the vulnerability of these composite types when exposed to fire restricts their use in areas where stringent fire safety conditions may not apply. Experimental determination at bench scale of composite particleboard fire behaviour has shown that the addition of flame retardants (FR) can delay the start and spread of fire. Bench scale data obtained in the cone calorimeter (CC) may not represent accurately a real scale fore behaviour during a fire scenario as documented by various researchers. The convolution model is a significant tool for predicting in real scale, fire behaviour of composites which depends on experimental inputs from CC data. In this paper, particleboards made from wood sawdust reinforced polyester composite were processed with FR at 0, 15 and $18 \%$ loading ratio using compression moulding technique. Test specimens cut from the FR-particleboards was exposed in horizontal orientation in the CC at $50 \mathrm{~kW} / \mathrm{m}^{2}$ to obtain experimental data and these were used as inputs to the prediction model. The predictive tool was used to predict the heat released rate and smoke production rate for the FR-particleboard. The results obtained shows that the FR-particleboard contributes very limited fire in real scale and compares well based on Euro-classification with particleboards from literature.
\end{abstract}

Keywords: Flame retardant, Particleboard, Convolution model, Real scale fire

\subsection{INTRODUCTION}

Wood residue with inherent lignocellulosic constituent embedded in polymer matrix which form a unified material structure material with distinct interface is a good example of modern-day composite materials. The development with ease of these composites during processing as well as their good mechanical properties per unit weight and durability make them favourable $[1,2]$. Wood from stem contains respectively $40-45 \%$ and 20 $30 \%$ cellulose and lignin less than most natural fibres [3]. The cellulosic content present in wood is responsible for the high release of flammable volatiles leading to high heat release rates. Notwithstanding, polymers also contributes a substantial amount of combustible volatiles. This has restricted their use in areas where stringent fire regulations do not exist. For the particleboard to meet current fire safety standards, several researchers $[4,5]$ have focused their attention to improve the flame retardancy of wood based polymer composites by traping combustible volatiles that can cause high release rates. Previous researches $[4,6]$ shows particleboards can be processed with flame retardants (FR). FR are chemical substances classified as either halogenated based FR or

*Corresponding author (Tel: +234 (0) 803746 3298)

Email addresses: suoware.research@gmail.com

(T.O Suoware), sylvester.edelugo@unn.edu.ng (S.O.

Edelugo), Ifeanyi.umeh@unn.edu.ng (S.I. Umeh). halogenated free FR that are incorporated into the particulate base composite during processing either by graft copolymerization [7] or intimately blended into the polymer using a high mechanical stirring device respectively. Hence, the effect of the FR on the composite fire properties can be tested experimentally in a bench scale but has shown limitations to accuracy compared to real scale testing.

A real or large-scale testing of composite materials is an important tool in the fire safety community. A real scale fire testing gives a better fire behaviour of composite materials but this approach is seemly impossible as it will require building a testing specimen to a room standard [8]. This is capital intensive and has been discouraged for purposes of academic research hence the prediction of HRR in real scale becomes a significant tool using various prediction models. Robson et al [9] predicted different polyurethane foam thickness using a modelling tool. The results obtained showed good agreement with experimental results. The convolution model (CM) is a significant tool used to predict the HRR of materials. The model is based on a time derivative area with the corresponding cone calorimeter data per unit area. Myllymakl and Baroudi [10] predicted the HRR of upholstery furniture using integral formulation. The results obtained were promising and agree with cone calorimeter data. Lie and Chan [11] predicted the HRR of industrial Nitrocellulose materials. The model was based 
on flame height data. The HRR predicted coincided well with cone calorimeter measure data. The main objective of the research paper is to develop and predict the heat release rate in real scale of a flame retardant particleboard using cone calorimeter data at $50 \mathrm{~kW} \cdot \mathrm{m}^{2}$ as input to the convolution model in Duhamel's integral. There is limited depth of information in real scale on the fire behavior particleboard. Prediction using the $\mathrm{CM}$ as a tool to predict the fire behaviour of particleboard is not available in literature to the best of the researcher's knowledge hence the necessity of exploring this tool and contribute to existing scientific knowledge of the fire behavior of FR particleboard.

\subsection{MATERIALS AND METHODS}

\subsection{Development of FR-WSP particleboard}

Fine ground wood sawdust (WS) as received was first treated with $5 \%(\mathrm{NaOH})$ solution for about $2 \mathrm{hrs}$ to improve the compatibility with the choice of resin: polyester. Afterwards, the particulates were washed with distilled water until blue litmus paper turned red which indicates that excess concentration of $\mathrm{NaOH}$ have been neutralized and then oven dried for 3 hrs to remove moisture content. The ready to use wood particles were used to produce the particleboard using compression moulding technique. The required quantities of the sawdust and polyester were used to produce the particleboards were obtained using volume fraction model [12]. Five particleboards were produced with six FR comprising $10 \mu \mathrm{m}$ of aluminium triOhtdroxide (ATH[Al2 $(\mathrm{OH}) 3]), 15 \mu \mathrm{m}$ of Ammonium polyphosphate (APP[(NH4PO3n), 300 $\mu \mathrm{m}$ of Gum Arabic powder (GAP) and $300 \mu \mathrm{m}$ of Carbon black (CB).

\subsection{Experimental method}

The cone calorimeter apparatus (CCA) was used to obtain data for the heat release rate of the particleboard according to ASTM E 1354. The specimens $(100 \mathrm{~mm} x$ $100 \mathrm{~mm} \times 10 \mathrm{~mm}$ ) cut from the OPFC fibreboard were

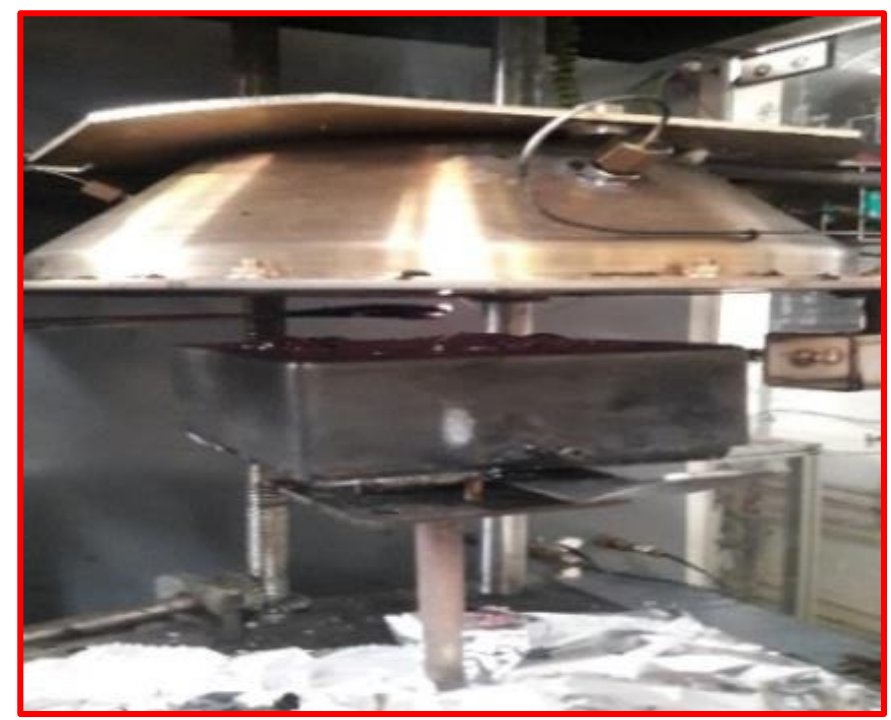

(a)

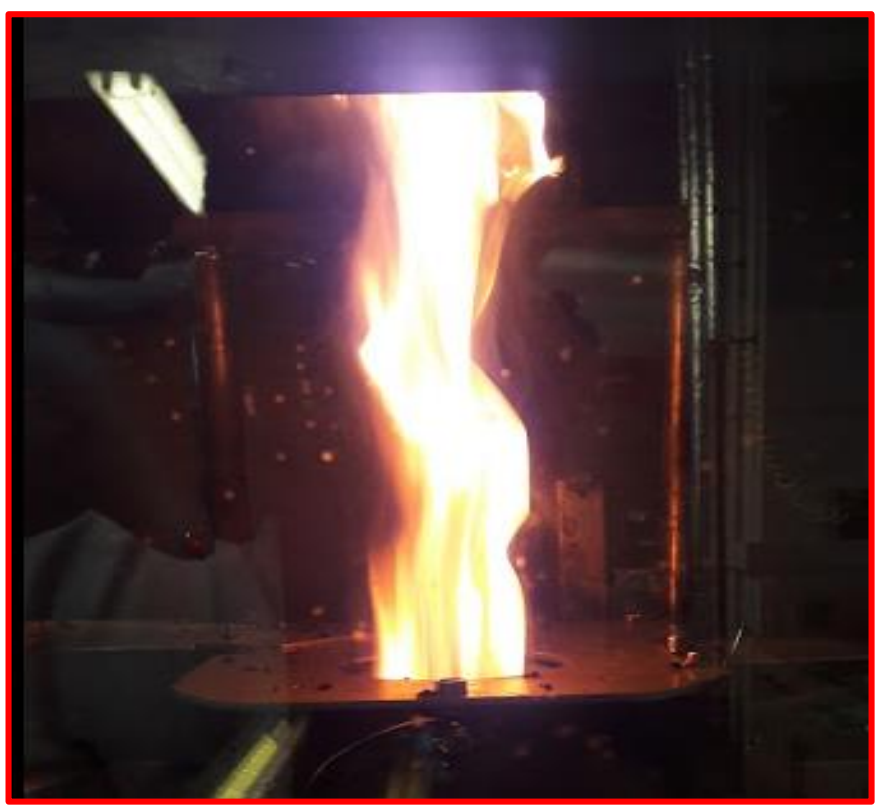

(b)

Figure 1: Cone calorimeter apparatus (a) Electric truncated cone shaped heater (b) Release of combustible products after removal of igniter.

wrapped in aluminium foil; along the side and bottom to reduce heat losses as specified in the standard. The specimens were exposed to $50 \mathrm{kwm}^{-2}$ heat flux horizontal orientation. An electric truncated cone shaped heater as shown in Fig 1a cause thermal decomposition and release combustible products from the specimen surface. The height between the cone heater and the surface of the specimen is maintained at $25 \mathrm{~mm}$. Ignition is produced by an intermediate piloted spark igniter located above the specimen and removed when the combustible products ignite as shown in Fig 1b. The process was repeated multiple times and a sensible result was recorded.

\subsection{Theoretical Approach}

The convolution model in Duhamel's integral (DI) was used to predict the particleboard heat release rate (HRR) and smoke production rate (SPR) for a single burning item in real scale. The DI is as shown in Eq. 1

$$
\begin{aligned}
& \mathrm{HRR}_{\mathrm{SBI}}=\int_{0}^{\mathrm{i}} \dot{\mathrm{A}}_{\mathrm{hrr}, \mathrm{eff}}(\tau) \dot{\mathrm{q}}^{\prime \prime}{ }_{\mathrm{cc}}(\mathrm{t}-\tau) \mathrm{d} \tau \approx \\
& \sum_{I=1}^{N} \Delta A_{h r r, e f f} \cdot \dot{q}^{\prime \prime}{ }_{C C}-1 \\
& S P R_{S B I}=\int_{0}^{i} \dot{A}_{s p r, e f f}(\tau) \dot{S}^{\prime \prime}{ }_{c c}(t-\tau) d \tau \approx \\
& \sum_{i=1}^{N} \Delta A_{s p r, e f f} \dot{S}_{c c}{ }^{\prime \prime N-i}
\end{aligned}
$$

Where: $\dot{q}^{\prime \prime}{ }_{C C}{ }^{N-1}=$ HRR per unit area as recorded in the cone calorimeter, $\dot{S}_{c c}{ }^{\prime \prime N-i}=$ SPR per unit area [1/s] measured in the cone calorimeter at time step $N-i .2$ $\Delta \dot{A}_{h r r, e f f}$ is the time derivative of the effective heat release $\left[\mathrm{m}^{2}\right], \triangle A S P R e f f, i$ increment in the effective 
smoke producing area at time step $I_{2} \mathrm{~N}$ is the total number of data recordings after ignition.

The effective HRR area and SPR area in Eq.1 and 2 were respectively obtained as shown below:

$A_{h r r, e f f}=A_{\max }\left[1+\left(1+\frac{t-\frac{t_{i g}}{2}}{t_{i g}}\right) \exp \left(-\frac{t-\frac{t_{i g}}{2}}{t_{i g}}\right)\right]$

$A_{S p r, e f f}=K_{S p r} \cdot A_{H R R, e f f}$

From Eq. 3 the time to ignition $t_{i g}$ was corrected using Eq. 5. This is necessary as the model was developed to be used for a heat flux at $40 \mathrm{~kW} / \mathrm{m}^{2}$.

$t_{\text {igCorr }}=t_{\text {igCone }}($ ConeFlux $/$ SBIFlux $)$

Similarly, in Eq. 4 the HRR was corrected using Eq.6 $H R R_{\text {Corr }}=H R R_{\text {Cone }}(\text { ConeFlux } / \text { SBIFlux })^{0.5}$ [6]

Where: $t_{i g \text { Corr }}=$ corrected ignition used in the model, $t_{\text {igcone }}=$ ignition time in the cone calorimeter, $H R R_{\text {Corr }}$ = corrected $\mathrm{HRR}, H R R_{\text {Cone }}=$ cone calorimeter HRR, ConeFlux $=$ flux in the cone calorimeter $50 \mathrm{~kW} / \mathrm{m}^{2}$ and SBIFlux $=$ corresponding reference flux for the cone SBI model being $40 \mathrm{~kW} / \mathrm{m}^{2}$.

The effective smoke producing area $A_{S p r, e f f}$ in Eq.4 is dependent on the burning product. The value of $K_{S P R}$ is based on a combination of 5 different variables connected to heat release and smoke production in the cone calorimeter. This is determined through three sets of Fisher's discriminant functions as shown:

$$
\begin{gathered}
\mathrm{F}_{\mathrm{A} 1}=-0.583 \mathrm{x}_{1}+31.986 \mathrm{x}_{2}+2.810 \mathrm{x}_{3} \\
+0.003424 \mathrm{x}_{4}+15.035 \mathrm{x}_{5} \cdot-98.974 \\
\mathrm{~F}_{\mathrm{A} 2}=-0.603 \mathrm{x}_{1}+26.9800 \mathrm{x}_{2}+2.511 \mathrm{x}_{3} \\
+0.01991 \mathrm{x}_{4}+14.373 \mathrm{x}_{5}-72.318 \\
\mathrm{~F}_{\mathrm{A} 3}=-0.885 \mathrm{x}_{1}+32.428 \mathrm{x}_{2}-1.653 \mathrm{x}_{3} \\
-0.01048 \mathrm{x}_{4}-5.302 \mathrm{x}_{5}-67.779
\end{gathered}
$$

If $\boldsymbol{A l}$ then, $K_{S P R}=0.3$ for products with low smoke production, If $\boldsymbol{A 2}$ then, $K_{S P R}=1.0$ for products with medium smoke production and, If $\boldsymbol{A} \mathbf{3}$ then, $K_{S P R}=2.5$ for products with high smoke production. Hence, the effective smoke producing area in Eq. 4 can be determined provided the heat release area is known.

The variables in Eq. 7 are defined as follows:

$x_{1}=T H R_{300 s}=$ the total heat release after $300 \mathrm{~s}$ obtained from cone calorimeter, $x_{2}=\ln \left(H R R_{\max }\right)=$ the maximum value of the heat release in the cone calorimeter, $x_{3}=$ $\ln \left(S P R_{\max }\right)=$ the maximum value of SPR in the cone calorimeter, $x_{4}=t_{i g}$ (or alternatively $\left.t_{S P R}\right)=$ the time to ignition in the cone calorimeter, $x_{5}=I_{H R R}$ is the index variable describing the applied route for development of $A_{S P R, e f f}$ in the HRR (SBI) prediction model. $I_{H R R}$ takes the values 1, 2 and 3 if HRR-route I, II and III are applied respectively as shown in Fig 2.

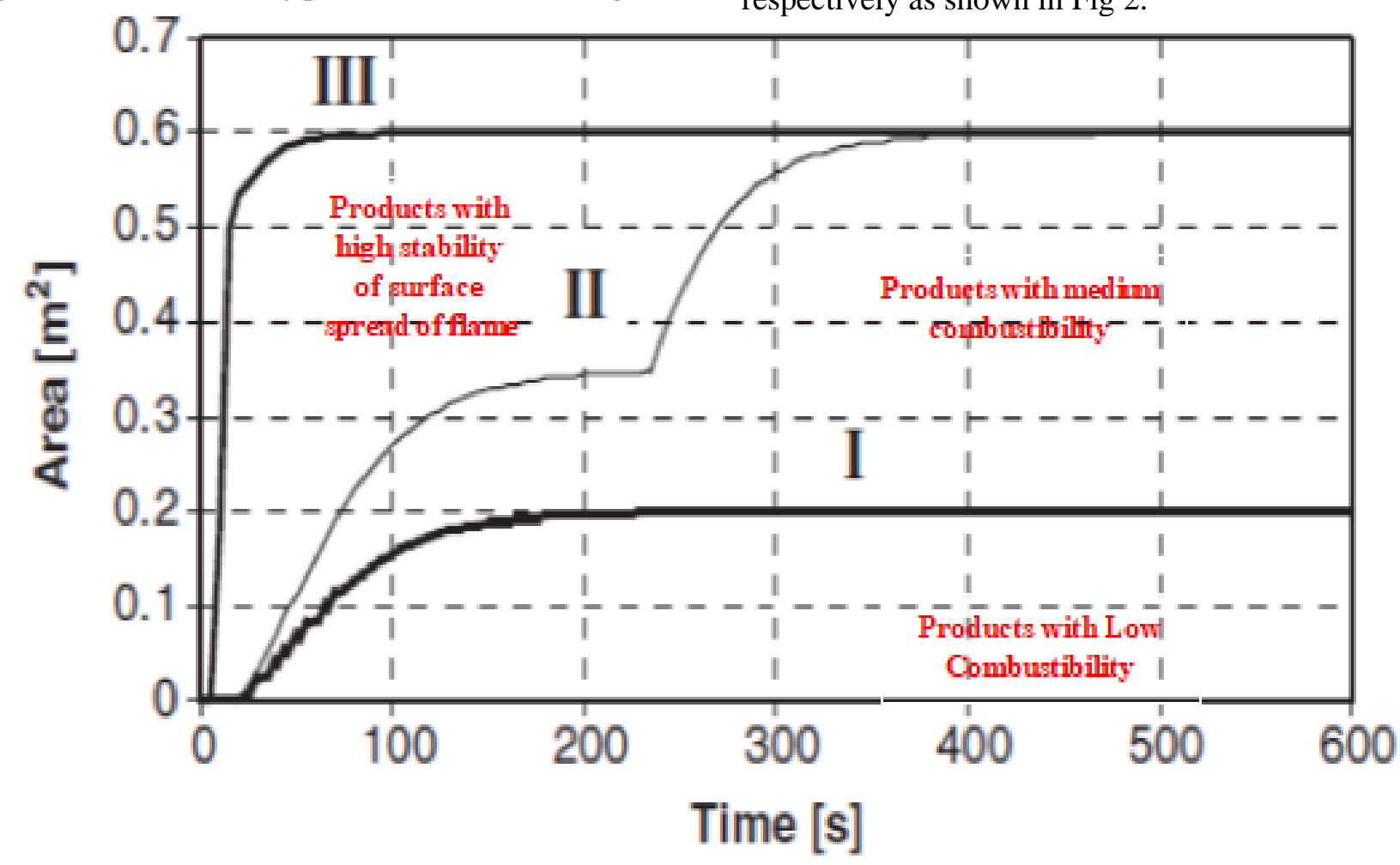

Figure 2: Suggestions of three different routes for development of the effective heat releasing area in the SBI test 
The composite panels developed were classified according to fire growth rate index (FIGRA) and smoke production growth rate index (SMPGRA) as shown respectively in Eq. 8 and 9. The calculation of the FIGRA is described in detailed in Hee et al [13]. FIGRA is defined as the growth rate of the burning intensity, HRR, during a test, for example the SBI test. FIGRA is calculated as the maximum value of the functional heat release rate over the elapsed test time as shown:

FIGRA Index $=1000 \mathrm{X} \max \left(\frac{\mathrm{HRR}_{(\mathrm{t})}}{\mathrm{t}}\right)[\mathrm{kW} / \mathrm{s}]$

\subsection{RESULTS AND DISCUSSIONS}

Figure 3 shows the profiles predicted by the model compared to the cone calorimeter data at $50 \mathrm{~kW} / \mathrm{m}^{2}$ and coincide well with each other. The profile is a series of predicted heat release rate $\left(\mathrm{HRR}_{\mathrm{SBI}}\right)$ curves in the single burning item (SBI). The predicted profile is seen to grow along the same paths with the measured profile in the cone calorimeter until it reaches its peak HRR and then declined. The prediction of the first peak is usually adequate for predicting correctly the fire behaviour of the particleboards in real scale. The early part of the curve is of major importance in determining the fire growth rate (FIGRA) used in the Euro-classification [14]. The FIGRA
SMOGRA is calculated as the growth rate of the maximum value of the smoke production rate over the elapsed test time as shown:

SMOGRA Index $=10,000 \mathrm{X} \max \left(\frac{\mathrm{SPR}_{(\mathrm{t})}}{\mathrm{t}}\right)\left[\mathrm{m}^{2} \mathrm{~s}^{-2}\right]$

Where:

$H R R_{(t)}=$ the heat release rate average over $30 \mathrm{~s}$ [in $\mathrm{kW}$ ], $S P R_{(t)}=$ the smoke production rate averaged over $60 \mathrm{~s}$ $\left[\mathrm{m}^{2} \mathrm{~s}^{-1}\right], t=$ time elapsed after the beginning of the test (s).

values obtained for the particleboards shows that 18\%ATH/APP-GAP-particleboard has the least FIGRA value at $37 \mathrm{~kW} / \mathrm{s}$ and then followed by $15 \%$ APP-GAP/CB-particleboard and $12 \%$ APP-GAP-particleboard respectively at $57 \mathrm{~kW} / \mathrm{s}$ and $58 \mathrm{~kW} / \mathrm{s}$ compared to those without flame retardant at $388 \mathrm{~kW} / \mathrm{s}$ (0\%-WSP) as shown in table 1 . This suggests that the APP-GAP effect made the particleboard to contribute limited fuel load to a sustained fire in real scale by trapping the release of combustible volatiles. GAP dehydrates the acid released from APP upon heating to form a stable char structure that prevented the release combustible volatiles.

Table 1: Predicted FIGRA and SMOGRA indices showing level of hazards of the WSP particleboard Specimen I. D

\begin{tabular}{|c|c|c|}
\hline \multirow[t]{2}{*}{ Specimen I. D } & \multicolumn{2}{|c|}{ Parameters } \\
\hline & FIGRA [kW/s] & SMOGRA $\left[\mathrm{m}^{2} / \mathrm{s}^{2}\right]$ \\
\hline 0\%WSP & 388 & 39 \\
\hline WSPC $12 \%$ ATH & 231 & 29 \\
\hline WSPC $12 \%$ APP-GAP & 58 & 10 \\
\hline WSPC $15 \%$ ATH/CB & 174 & 17 \\
\hline WSPC $_{15 \% A P P-G A P / C B}$ & 57 & 3 \\
\hline WSPC18\%ATH/APP-GAP & 37 & 0 \\
\hline
\end{tabular}

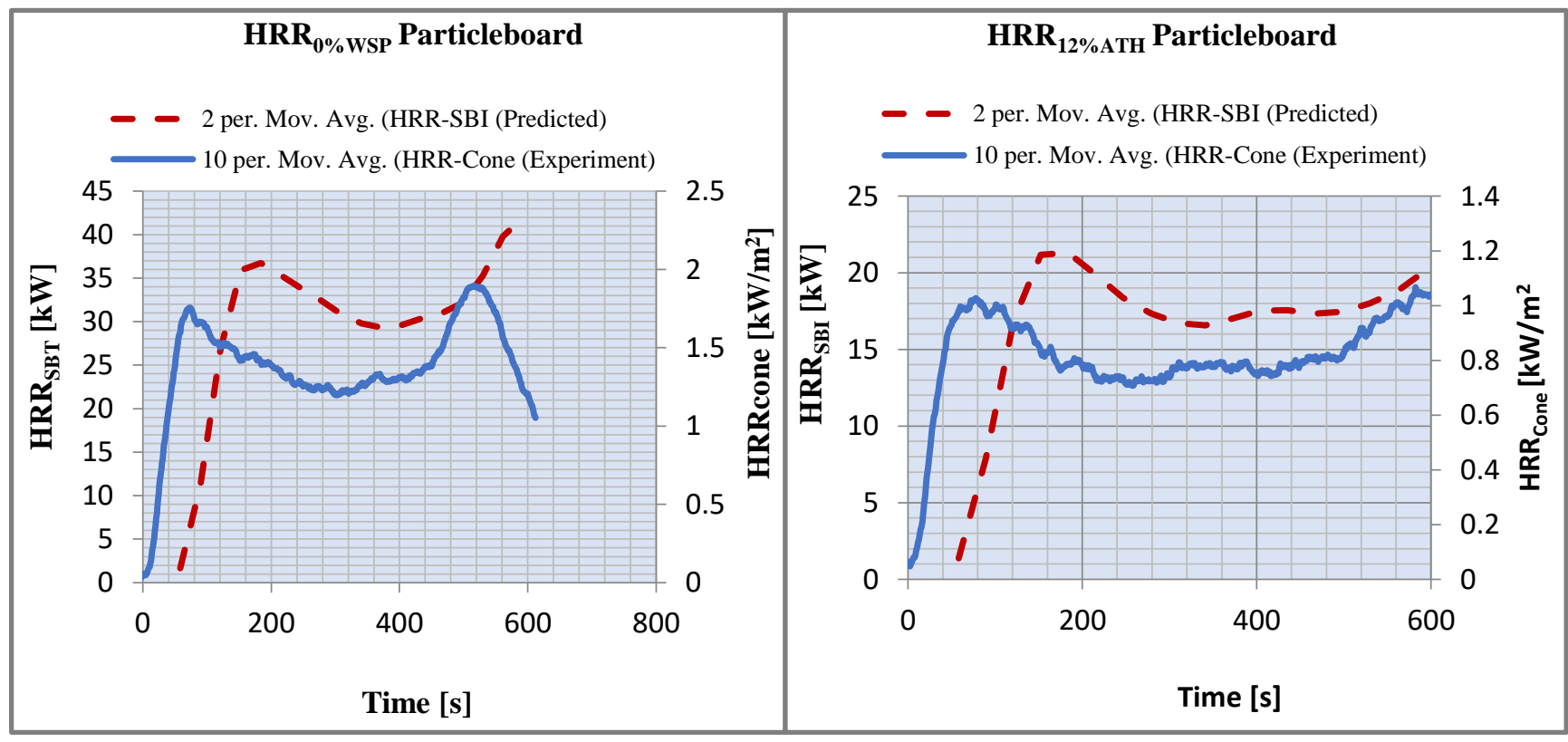




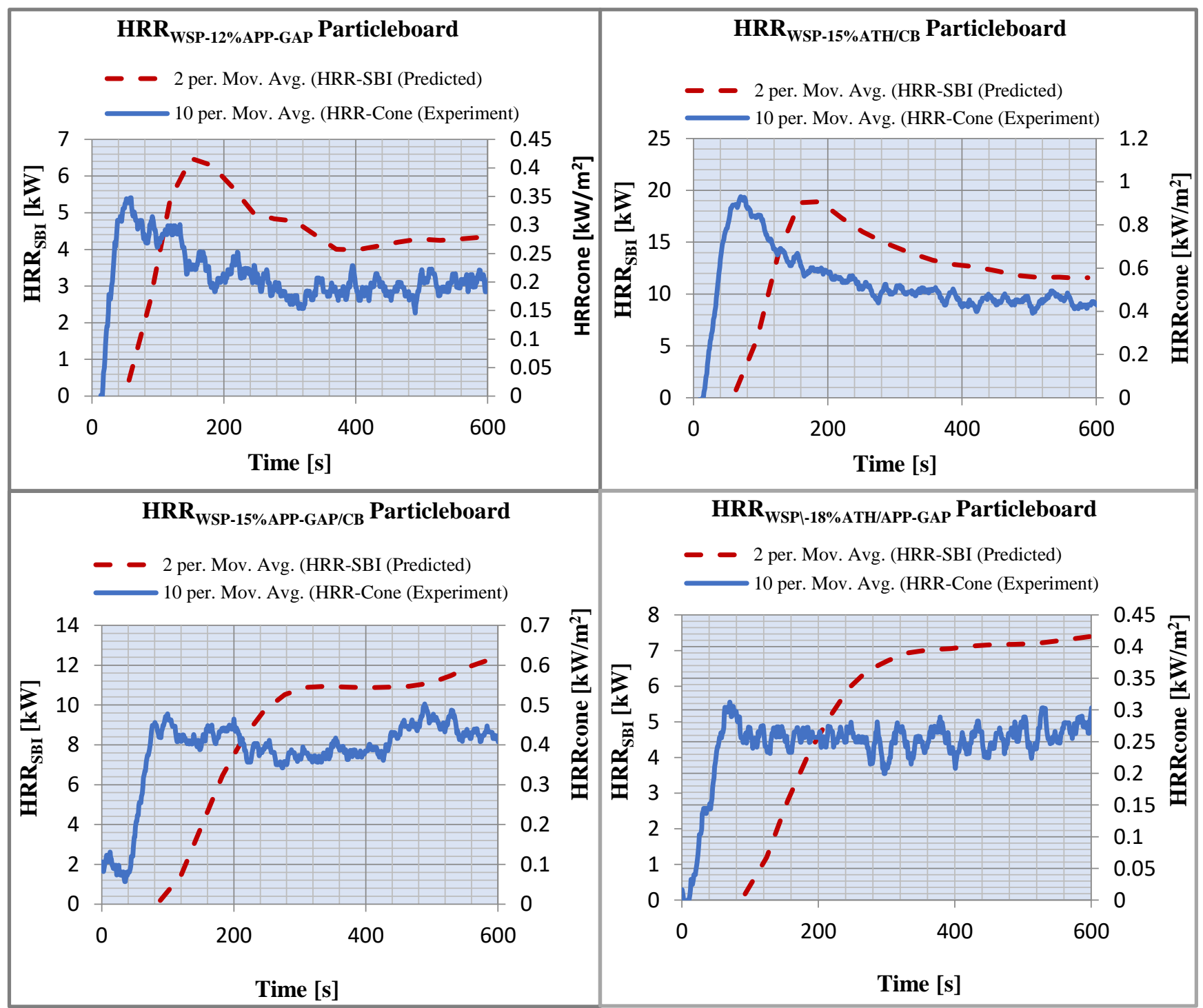

Figure 3: Shows predicted curves of the heat release rate in the SBI compared to cone calorimeter HRR data of the WSP particleboard

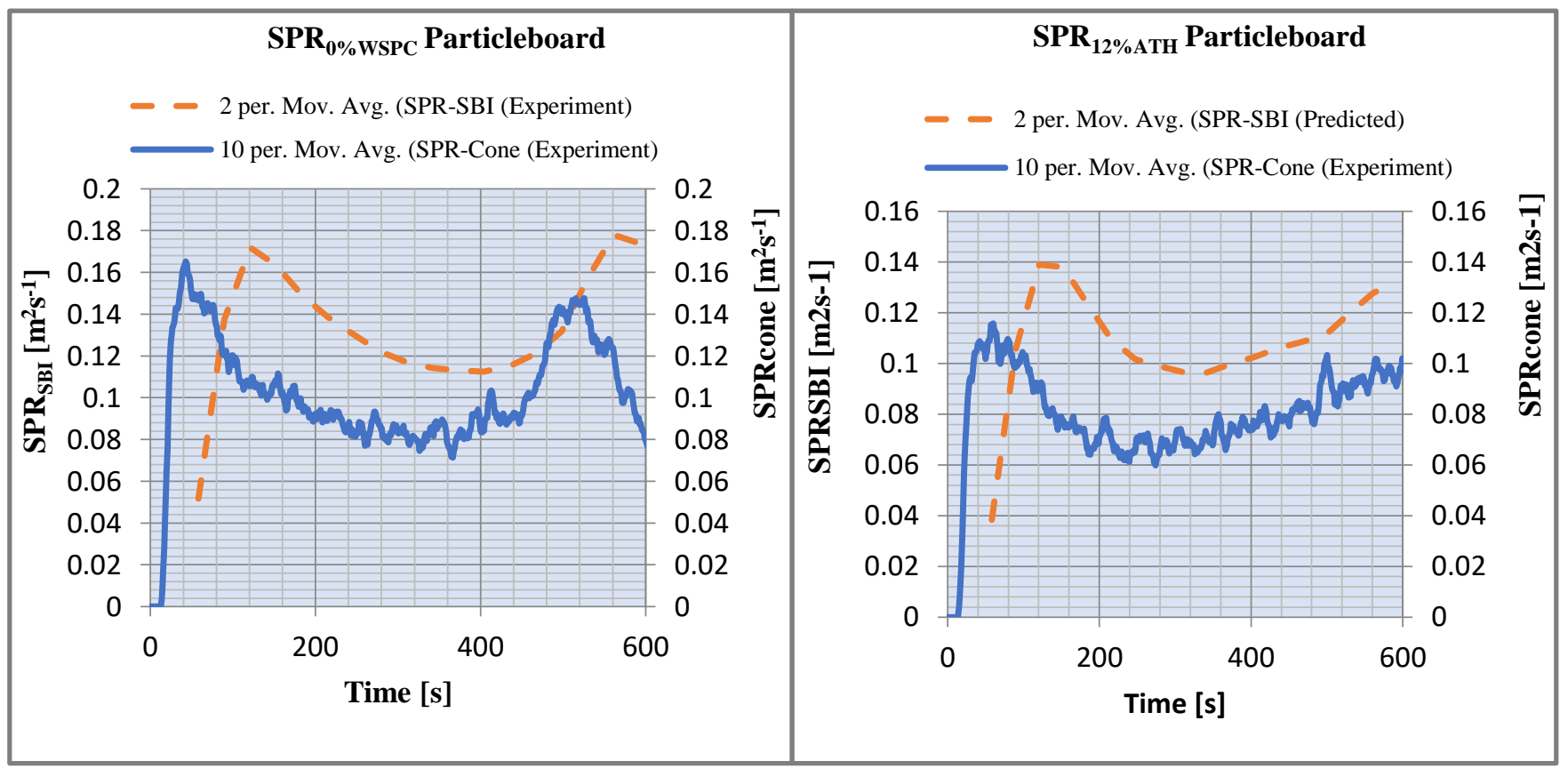




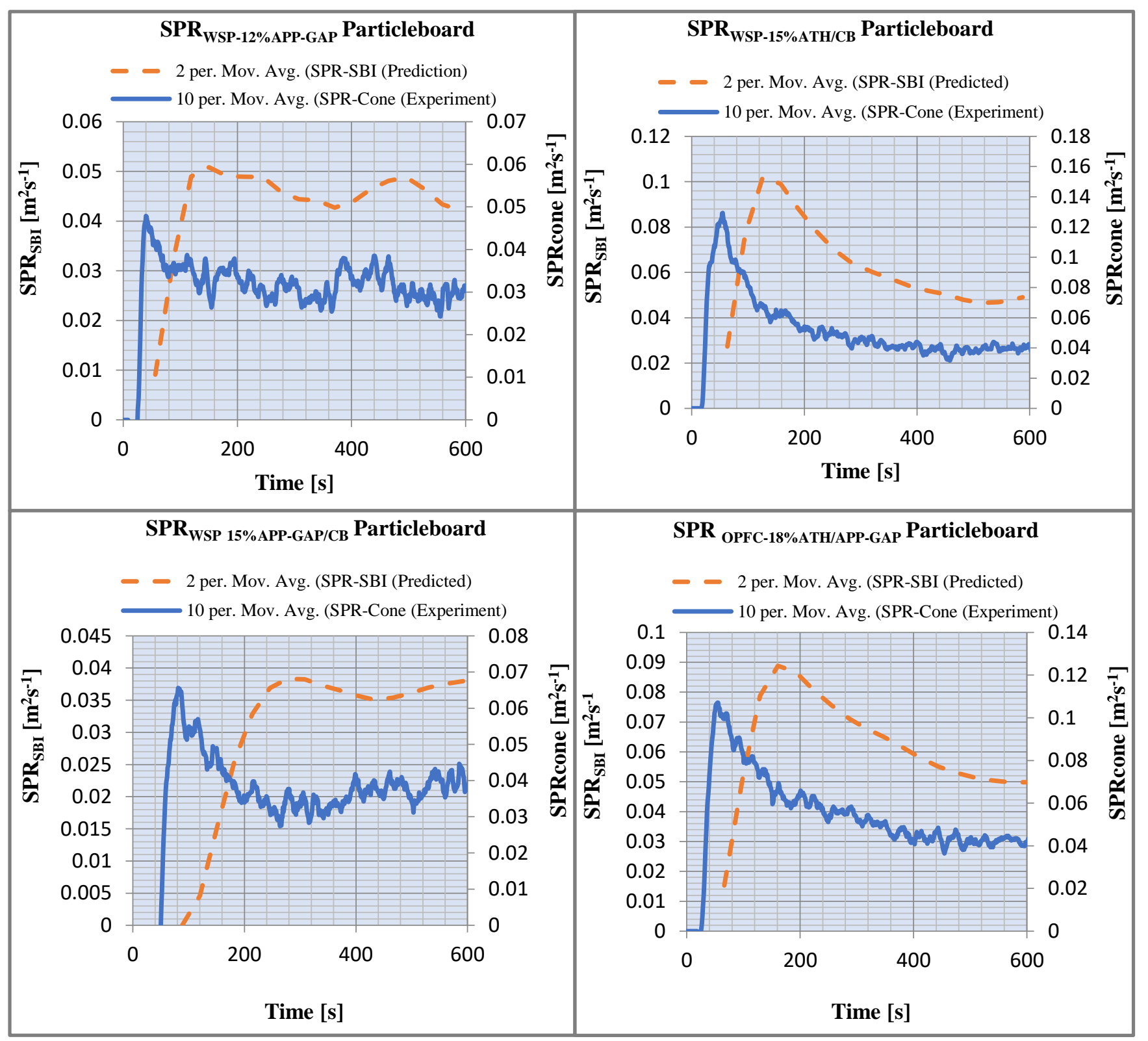

Figure 4: Shows predicted curves of the Smoke production rate in the SBI compared to cone calorimeter SPR data of the WSP particleboard

Figure 4 show the corresponding smoke production rate (SPR) and reveals a similar corresponding trend with the heat is released rate and suggests the release of smoke accompanied with toxic gases as heat is evolved into the atmosphere. Smoke production is an important fire property in determining the suitability of materials for building applications. The SMOGRA value obtained reveals that the $18 \%$ ATH/APP-GAP-particleboard followed by $12 \%$ APP-GAP-particleboard suppressed better the smoke produced with a SMOGRA of $3 \mathrm{~m}^{2} / \mathrm{s}^{2}$ and $10 \mathrm{~m}^{2} / \mathrm{s}^{2}$ respectively compared to those without FR at $39 \mathrm{~m}^{2} / \mathrm{s}^{2}$ as shown in table 1 . This implies that mechanism of APPGAP interacted with the heat released to produce less smoke in real scale. In Figure 5 a comparison of the various particleboards with those from literature was classified based on Euro-classification system. It shows the FIGRA and SMOGRA for 12\%APP-GAP-particleboard, 15\%APP-GAP/CB-particleboard and 18\%ATH/APP-GAP particle board falls within the same cell with flame retardant chip board and flame-retardant fire-retardant spruce panel from literature and suggests the panels fall within similar fire safety standard. It indicates that the particleboards contributed very limited fuel load in real scale and was placed as class $B-S_{1}$ materials suitable for used for walls and ceilings, interior furnishing, and doors and separating walls applications. The poorest particleboard on the other hand was found for $0 \%$-WSP particleboard with FIGRA and SMOGRA placed in class $\mathrm{D}-\mathrm{S}_{2}$. 


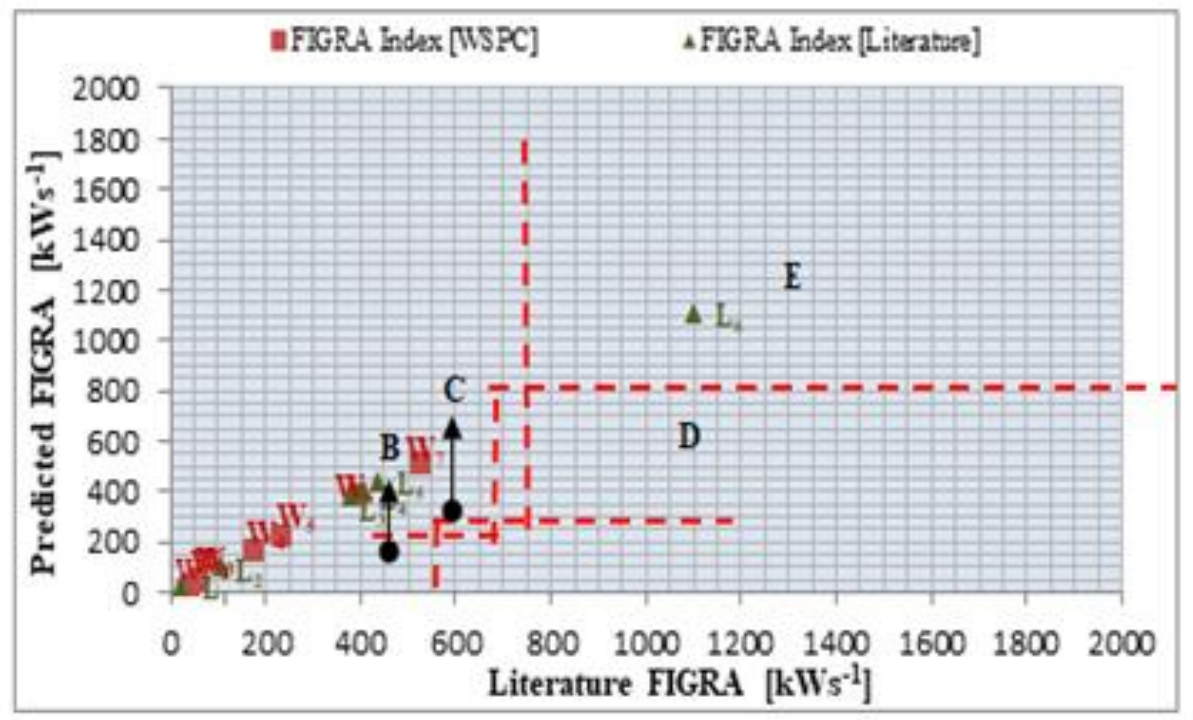

\begin{tabular}{|c|c|}
\hline \multicolumn{2}{|c|}{ FIGRA Class } \\
\hline 0\%-WSP particleboard & D \\
\hline WSPC $_{12 \% \text { ATH particleboard }}$ & $\mathrm{C}$ \\
\hline WSPC $_{12 \% A P D-G A P}$ particleboard & B \\
\hline 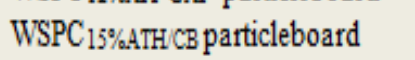 & $\mathrm{C}$ \\
\hline WSPC $_{15 \% \text { APP-GAPCB particleboard }}$ & B \\
\hline WSPC $_{18 \% A T H / A P P G A P p a r t i c l e b o a r d}$ & B \\
\hline $\mathrm{L}_{1}$ & B \\
\hline $\mathrm{L}_{2}$ & B \\
\hline $\mathrm{L}_{3}$ & D \\
\hline $\mathrm{L}_{4}$ & D \\
\hline $\mathrm{L}_{5}$ & D \\
\hline I & $\mathbf{E}$ \\
\hline
\end{tabular}

(a)
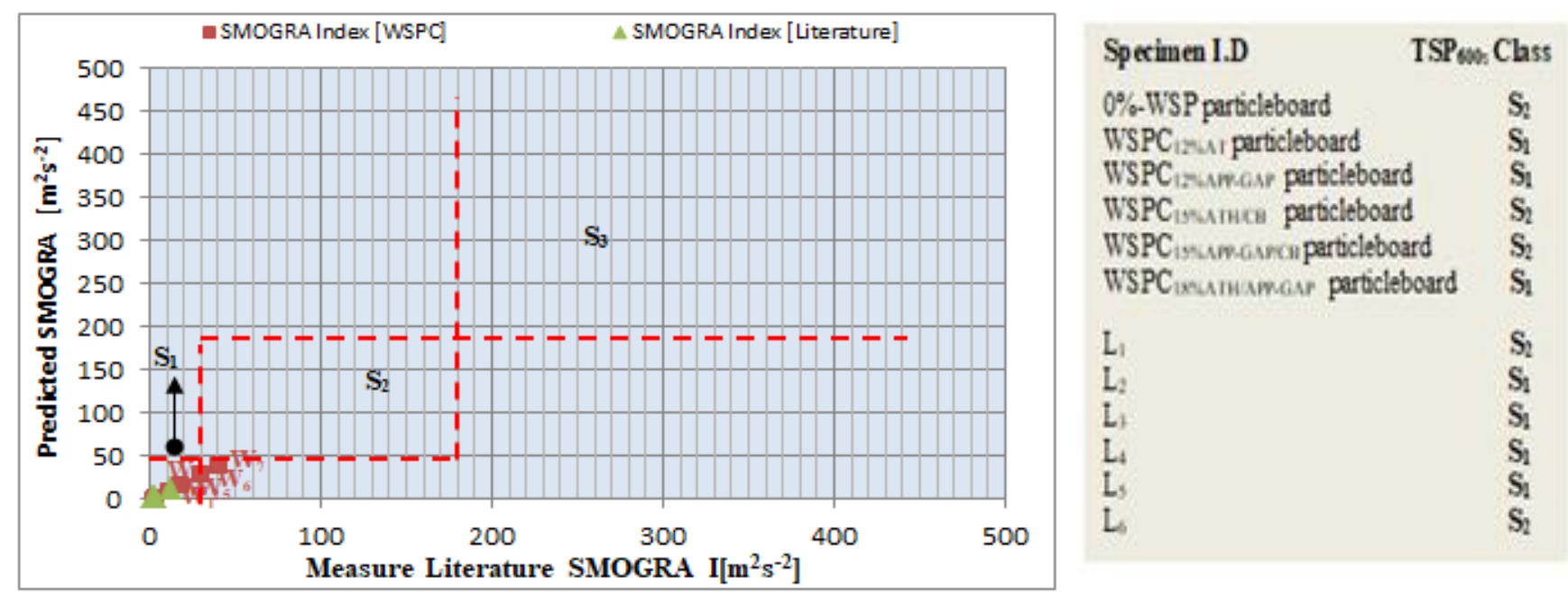

(b)

Figure 5: Comparison of literature and predicted (a) FIGRA indices (b) SMOGRA Indices of the WSP particleboard. The dashed lines indicate the class limits.

$L_{1}=$ Flame retardant chip board, $L_{2}=$ Flame retardant Fire Retardant Spruce Panel, L3: Melamine-faced particle board, L4: Ordinary particle board, L5: Mass timber (spruce) unvarnished, L6: Low density fibreboard

\subsection{CONCLUSIONS}

This main objective of this research paper is to develop and predict with the convolution model in Duhamel's integral, the effect of flame retardant on the heat release rate and smoke production in real scale. Therefore, this paper concludes as follows:

i. Six flame retardants processed with WSP particleboard shows that it is effective in reducing heat release rate and smoke production rate with the 18\%ATH/APP-GAP-particleboard exhibiting superiority in real scale as it contributed limited fire and smoke by FIGRA and SMOGRA classification respectively.

ii. The convolution model in Duhamel's integral for the HRR $_{\mathrm{SBI}}$ and $\mathrm{SPR}_{\mathrm{SBI}}$ shows closely related trajectorially with the cone calorimeter data at
$50 \mathrm{~kW} / \mathrm{m}^{2}$, confirming the convolution model could be used to predict the fire behaviour of particleboards in real scale.

iii. The FIGRA values for ${ }_{12} \%$ APP-GAP-particleboard, 15\%APP-GAP-particleboard and 18\%ATH/APP-GAPparticleboard were predicted to be $58 \mathrm{~kW} / \mathrm{s}$, $57 \mathrm{~kW} / \mathrm{s}$ and $3 \mathrm{~kW} / \mathrm{s}$ respectively while SMOGRA values were predicted to be $10 \mathrm{~m}^{2} / \mathrm{s}^{2}, 17 \mathrm{~m}^{2} / \mathrm{s}^{2}$ and $3 \mathrm{~m}^{2} / \mathrm{s}^{2}$ respectively which placed the class of particleboards in $\mathrm{B}-\mathrm{S}_{1}$ indicative of very limited contribution to fire in real scale.

iv. Based on FIGRA and SMOGRA predictions, the for $\quad 12 \%$ APP-GAP-particleboard, $15 \%$ APP-GAPparticleboard and 18\%ATH/APP-GAP-particleboard could be safe to meet fire safety standards for interior furnishing of buildings applications. 


\section{ACKNOWLEDGEMENT}

The authors of this work wish to acknowledge the financial support from Tertiary Educational Trust fund (TETFUND) institutional based Research, University of Nigeria, Nsukka.

\section{REFERENCES}

[1] Frederick, T.W. and Norman, W. "Natural Fibres Plastics and Composites" Kluwer Academic Publishers, New York, (2004).

[2] Mohanty, A.K., Misra, M. and Drzal, L.T. "Natural Fibers, Biopolymers and BioComposites" Taylor \& Francis Group, LLC, ISBN 0-8493-1741-X, Boca Raton, FL, USA, (2005).

[3] Suoware T.O., Edelugo S.O. and Ezema I.C. "Flammability of flame retarded natural fibre composites and application in automobile interior: A review." International Journal of Interdisciplinary Research (IJIR), 3(8), (2017), 587-600.

[4] Schirp, A. and Su, S. "Effectiveness of pre-treated wood particles and halogen-free flame retardants used in wood-plastic composites." Polymer Degradation and Stability, 126, (2016), 81-92.

[5] Wang, W., Zhang, S., Wang, F., Yan, Y., Li, J. and Zhang, W. "Effect of microencapsulated ammonium polyphosphate on flame retardancy and mechanical properties of wood flour/polypropylene composites." Polymer Composites, 37(3), (2016), 666-673.

[6[ Khalili, P., Tshai, K.Y. and Kong, I. "Natural fiber reinforced expandable graphite filled composites: Evaluation of the flame retardancy, thermal and mechanical performances." Composites Part A: Applied Science and Manufacturing, 100, (2017), 194205.
[7] Bhattacharya, A. and Misra, B.N. "Grafting: a versatile means to modify polymers: techniques, factors and applications." Progress in polymer science, 29(8), (2004), 767-814.

[8] EN 13501-1. "Fire Classification of Construction Products and Building Elements-Part 1: Classification using Test Data Form Reaction to Fire Test". (2002).

[9] Robson, L.D., Torvi, D.A., Obach, M.R. and Weckman, E.J. "Effects of variations in incident heat flux when using cone calorimeter test data for prediction of full-scale heat release rates of polyurethane foam." Fire and Materials, 40(1), (2016), 89-113.

[10] Myllymakl, J. and Baroudi, D. "Prediction of Heat Release Rate of Upholstery Furniture using Integral Formulation". Proceedings of the interflam '96. University of Cambridge, England, 26-28, (1996), 27-36.

[11] Lie, H. and Mingyi, C. "A simplified method to predict the heat release rate of industrial nitrocellulose materials." Applied Sciences, 8(6) (2018), 910.

[12] Suoware, T.O., Edelugo, S.O. and Ezema I.C. "Impact of Hybrid flame Retardant on the Flammability and Thermomechanical Properties of Wood Sawdust Polyester Composite Panel" Fire and Materials, 43 (3), (2019), 335-343.

[12] Van Hees, P., Hertzberg, T. and Steen-Hansen, A. "Development of a screening method for the SBI and room corner using the cone calorimeter." Swedish National Testing and Research Institute, Wordiest Project, (2002), 1479-00

[14] Messerschmidt, B., Van Hees, P. and Wickström, U. "Prediction of SBI (Single Burning Item) test results by means of cone calorimeter test results." Interflam 1999. 8th International Fire Science and Engineering Conference, Edinburgh, Scotland, (1999), 11-22. 